\title{
MERIS observations of phytoplankton phenology in the Baltic Sea
}

\author{
Daoxi Zhang ${ }^{\mathrm{a}, \mathrm{b}, *}$, Samantha Lavenderc,d, Jan-Peter Muller ${ }^{\mathrm{b}}$, David Walton ${ }^{\mathrm{b}}$, \\ Xi Zou ${ }^{a}$, Fang Shi ${ }^{a}$ \\ ${ }^{a}$ Key Laboratory of Ecological Impacts of Hydraulic-Projects and Restoration of Aquatic \\ Ecosystem of Ministry of Water Resources, Institute of Hydroecology, Ministry of Water \\ Resources and Chinese Academy of Sciences, Wuhan 430079, P.R.China \\ ${ }^{b}$ Mullard Space Science Laboratory, Department of Space and Climate Physics, \\ University College London, Holmbury St. Mary, Dorking, Surrey RH5 6NT, U.K. \\ ${ }^{c}$ Pixalytics Ltd, Plymouth Science Park, 1 Davy Road, Plymouth, Devon PL6 8BX, U.K. \\ ${ }^{d}$ School of Marine Science and Engineering, \\ University of Plymouth, Drake Circus, Plymouth, Devon PL4 8AA, U.K.
}

\begin{abstract}
The historical data from the MEdium Resolution Imaging Spectrometer (MERIS) is an invaluable archive for studying global waters from inland lakes to open oceans. Although the MERIS sensor ceased to operate in April 2012, the data capacities are now re-established through the recently launched Sentinel-3 Ocean and Land Colour Instrument (OLCI). The development of a consistent time series for investigating phytoplankton phenology features is crucial if the potential of MERIS and OLCI data is to be fully exploited for inland water monitoring. This study presents a time series of phytoplankton abundance and bloom spatial extent for the highly eutrophic inland water of the Baltic Sea using the 10-year MERIS archive (2002-2011) and a chlorophyll-a based Summed Positive Peaks (SPP) algorithm. A gradient approach in conjunction with the histogram analysis was used to determine a global threshold from the entire collection of SPP images for identifying phytoplankton blooms from the background water. This allows spatio-temporal dynamics of daily bloom coverage, timing, phyto-
\end{abstract}

\footnotetext{
* Corresponding author.

Email address: dxzhang@mail.ihe.ac.cn (Daoxi Zhang)
} 
plankton abundance and spatial extent to be investigated for each Baltic basin. Furthermore, a number of meteorological and hydrological variables, including spring excess phosphate, summer sea surface temperature and photosynthetically active radiation, were explored using boosted regression trees and generalised additive models for investigating the ecological response of phytoplankton assemblages to environmental perturbations and potential predictors of summer blooms. The results indicate that the surface layer excess phosphate available in February and March had paramount importance over all other variables considered in governing summer bloom abundance in the major Baltic basins. This finding allows new insights into the development of early warning systems for summer phytoplankton blooms in the Baltic Sea and elsewhere.

Keywords: Remote sensing, Baltic Sea, Phytoplankton abundance, Bloom extents, Excess phosphate

\section{1. Introduction}

Over the last few decades, coastal eutrophication has been considered as a serious threat to marine ecosystems (Paerl, 1997; Smith, 2003; Lundberg et al., 2005; Andersen et al., 2010; Fleming-Lehtinen et al., 2015). Dense algal blooms limit light availability in the water column, restricting growth and causing the death of submerged aquatic vegetation in coastal zones (Chislock et al., 2013). Nuisance algal blooms also taint water resources, causing purification difficulties for drinking water supplies and disrupting recreational and tourism activities. Additionally, poisonous substances produced by toxic algal blooms pose a health hazard to the public (Hunter, 1998; Backer et al., 2010a).

To address eutrophication and its associated adverse effects on the environment, extensive efforts have been made by government agencies and environmental organisations. Subsequently, conventions and directives were put in place 
for defining strategies for eutrophication assessment and management. For instance, the Oslo-Paris Convention for the Protection of the North-East Atlantic (knowns as the OSPAR Convention) entered into force in 1998. To achieve the primary objective of maintaining a healthy marine environment without eutrophication, the Ecological Quality (EcoQ) elements and Ecological Quality Objectives (EcoQOs) incorporating the most severe effects of water quality (e.g. toxic algal blooms, the loss of submerged vegetation etc.) were proposed to monitor and assess biological responses to nutrient enrichment. Evaluation of the EcoQOs involves a comparison between the region-specific reference levels and monitoring data collected routinely for each EcoQ indicator, including chlorophyll-a (Chl-a), winter nutrient concentrations and oxygen deficiency levels (OSPAR, 2005, 2008). A similar scheme has been adopted by the Baltic Sea Action Plan: BSAP (HELCOM, 2007) for the eutrophication assessment in the Baltic Sea. One of the crucial steps in implementing these programmes is to set a suitable reference level as an objective. Within the OSPAR Convention, the reference level is determined by the analysis of long-term historical monitoring data to derive the 'pristine' condition. However, for most water bodies, historical monitoring records are either unavailable or insufficient (Painting et al., 2005). Although BSAP adopted an alternative approach to use both historical data and modelling, this is still challenging for several water monitoring programmes due to the limited technical supports (HELCOM, 2009; Backer et al., 2010b). Another factor hampering the establishment of reliable eutrophication assessments is the restricted spatial coverage and limited temporal frequency of in situ sampling programmes; the spatial distribution of algal blooms is usually both patchy and transient. Thus, sampling at a few pre-defined stations (e.g. 42 stations under BSAP) at monthly, seasonal or even annual frequency (Ferreira et al., 2011) is generally insufficient. Therefore, alternative monitoring methods 
are needed.

Since the launch of the first ocean colour sensor, the Coastal Zone Color Scanner (CZCS) in 1978, satellite remote sensing techniques have been widely applied to various environmental programmes. It is now one of the most effective means to acquire spatially and temporally cohesive daily information on global waters. The cost effective accessibility and long-term availability have made it a vital and practical tool in aquatic studies (Brando \& Dekker, 2003; Hu et al., 2004; Platt et al., 2009; Matthews et al., 2010; Zhang et al., 2015; Alikas \& Kratzer, 2017), including retrieving phytoplankton pigments (Kutser, 2004; Simis et al., 2005; Gitelson et al., 2009; Moses et al., 2009; Al-Naimi et al., 2017), estimating Coloured Dissolved Organic Matter (CDOM) (Dall'Olmo et al., 2017) and Total Suspended Solids (TSS) (Chen et al., 2007a,b). To detect and map phytoplankton blooms in optically complex inland and coastal waters, ocean colour indices have been demonstrated as one promising approach (Gower et al., 2005, 2006; Hu, 2009; Hu et al., 2010; Matthews et al., 2012; Matthews, 2014; Palmer et al., 2015; Hu \& Feng, 2017). These approaches generally take advantage of the red-NIR reflectance peaks measured in Bottom of Rayleigh Reflectance (BRR) for estimating phytoplankton abundances and bloom distributions. In particular, the Floating Algae Index (FAI, Hu 2009) was proposed to study the time series of floating algal blooms in eutrophic lakes in China $(\mathrm{Hu}$ et al., 2010; Zhang et al., 2015). The Maximum Peak Height algorithm (MPH, Matthews et al. 2012) was applied to South African inland waters for investigating the long-term trend of cyanobacterial blooms (Matthews, 2014). In the Baltic Sea, however, both FAI and MPH approaches have been shown to be inapplicable to the general bloom case where the surface biomass can be relatively low (Hu, 2009; Matthews et al., 2012). Although an alternative thresholding method was adopted to establish a long-term bloom record for the Baltic region 
(Kahru et al., 2007; Kahru \& Elmgren, 2014), the bias related to the arbitrarily defined bloom threshold is difficult to identify.

The Summed Positive Peaks (SPP) algorithm, originally developed for estimating phytoplankton abundances (Chl-a) (see Zhang et al. 2017), provides an insight into the study of phytoplankton dynamics in the Baltic Sea. The SPP approach uses MERIS BRR corrected for gaseous absorption and Rayleigh scattering, which avoids complicated and error-prone atmospheric aerosol correction procedures. In addition, summation of the positive reflectance line heights makes it sensitive and applicable to the general bloom case. Despite the fact that the MERIS data is no longer actively acquired, the data continuity is now re-established by recently launched OLCI operated on the European Space Agency's (ESA) Sentinel-3 satellites. Hence, it is of key importance to investigate spatio-temporal dynamics of phytoplankton abundance if the potential of MERIS and OLCI data is to be fully exploited.

In this paper, we apply the SPP approach to the Baltic Sea to establish a time series of phytoplankton phenology (intensity, timing and bloom extent) using the 10-year MERIS data archive (2002 to 2011), aiming to understand phytoplankton dynamics and their ecological responses to environmental perturbations. Specifically, our objectives are to (1) quantify the seasonal and interannual variability of phytoplankton assemblages within the major Baltic basins, alongside the bloom spatial extents; (2) determine the relationship between summer phytoplankton abundance and hydrological, meteorological factors, in an attempt to develop ecological models for estimating summer blooms in the Baltic Sea. 


\section{Materials and methods}

\subsection{Study site}

Being a semi-enclosed shallow brackish water body located in northern Europe, the Baltic Sea has been considered as one of the largest inland seas affected by eutrophication (HELCOM, 2009; Pyhälä et al., 2013). It receives hazardous compounds from various sources, including industry, agriculture, shipping and recreational activities (Lotze et al., 2006). The Baltic Sea can be partitioned into several sub-regions by its shallow sills. For instance, the Danish Straits are separated from the major part of the sea by two shallow sills: the Darss Sill and the Drodgen Sill (Daewel \& Schrum, 2013). The remaining section of the Sea is divided into a number of basins, including the Baltic Proper (BoP), Gulf of Riga (GoR), Gulf of Finland (GoF) and Gulf of Bothnia (GoB), where BoP can be further separated into the Southern and Northern Baltic Proper (SBP and NBP) alongside Western and Eastern Gotland Basin (WGB and EGB). GoB consists of the Bothnian Sea (BoS) and Bothnian Bay (BoB), see Figure 1. All these basins are separated from the adjacent regions by shallow sills, except GoF.

The Baltic Sea is a unique and complex brackish water ecosystem, acting as the indispensable habitat for various species such as macro-algae, marine mammals and sea birds; it also produces diverse natural and economic resources for the surrounding countries (Swedish EPA, 2008). Over the last few centuries, however, the Baltic ecosystem has changed dramatically. It has shifted from oligotrophy to an eutrophic state (Österblom et al., 2007), and is still influenced by anthropogenic pressures from densely populated catchment areas.

Nutrient inputs, either through rivers and estuaries or direct discharges from pollution sources, significantly affect the Baltic ecosystem with waterborne nutrients contributing most of the new nutrient budget into the system. During 


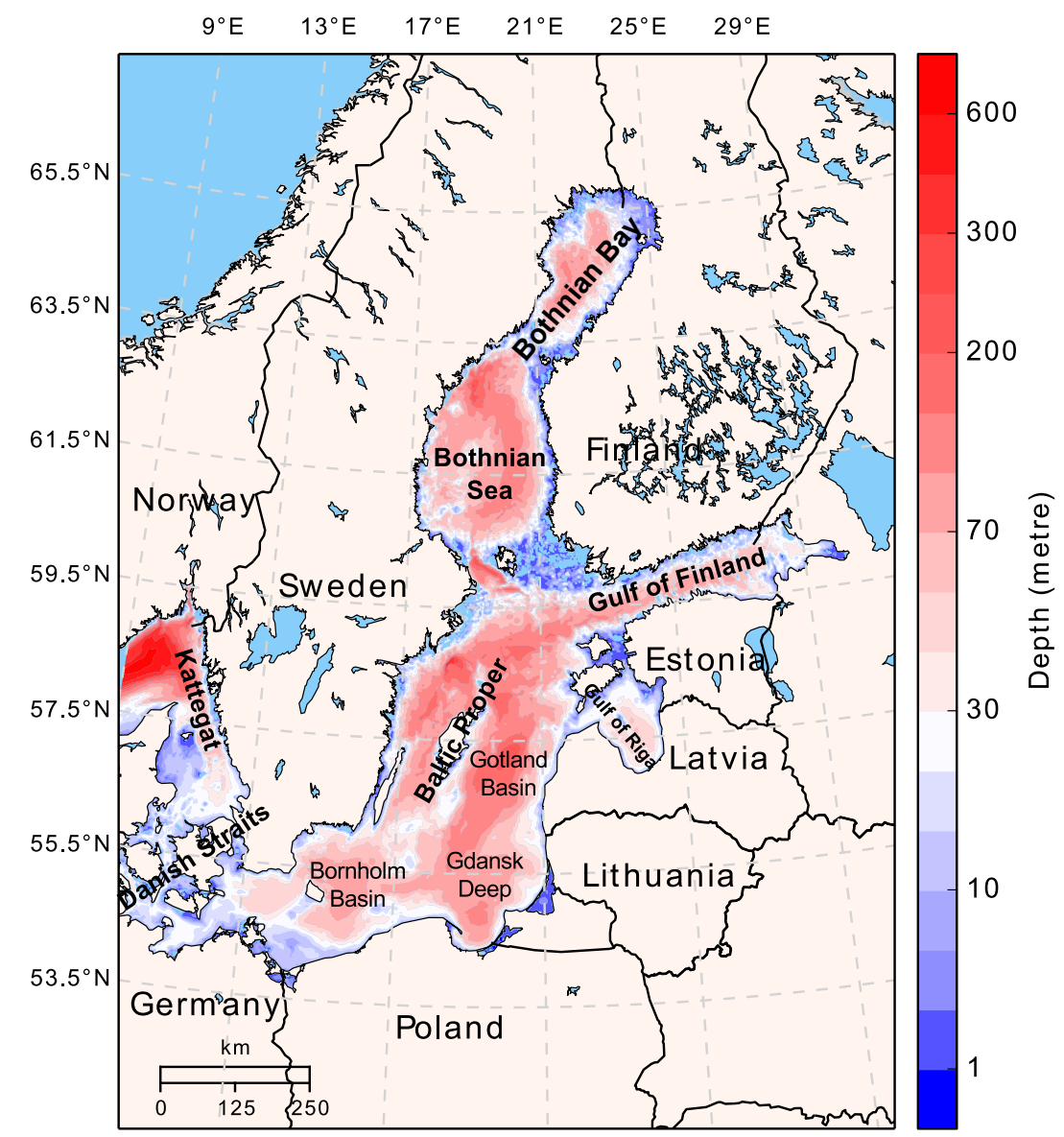

Figure 1: Topographic map of the Baltic Sea and the major basins including BoB, BoS, GoF, GoR and BoP. Topographic dataset was obtained from Leibniz Institute for Baltic Sea Research (http://www.io-warnemuende.de/topography-of-the-baltic-sea.html).

2001 and 2006, for instance, the average annual total input of waterborne nutrients contributed $75 \%$ of the total nitrogen (up to 641,000 tons) and $95 \%$ of the total phosphorus (up to 30,200 tons) (HELCOM, 2009). In addition, airborne nitrogen through atmospheric deposition over land waters also contributes significantly to the remaining proportion of the nutrient budget; it has been shown that around $25 \%$ of the total nitrogen input into the Baltic Sea was through atmospheric deposition (HELCOM, 2009). In contrast, the contribution of air- 
borne phosphorus to the system is relatively small, amounting to $1-5 \%$ of the total phosphorus input (HELCOM, 2006). Due to limited water exchange with the North Sea, the high nutrient levels generally remain in the Baltic Sea for up to decades, resulting in nutrient over-enrichment or eutrophication and posing a serious threat to the ecosystem.

Nutrient levels and light availability are two major factors governing seasonal phytoplankton biomass and species composition (Wasmund et al., 2008). Generally, when the water column is well mixed in the spring, a sufficient amount of nitrogen and phosphorus supports the growth of diatoms and dinoflagellates and facilitates the formation of spring blooms (Yurkovskis et al., 1999; Carstensen \& Heiskanen, 2007). When persistent light becomes available during the summer, the excessive amount of dissolved inorganic phosphate promotes the growth of nitrogen fixing cyanobacteria such as Nodularia spumigena and Aphanizomenon flos-aquae, resulting in the proliferation of surface cyanobacterial blooms. As phytoplankton assemblages can rapidly respond to environmental changes, the species composition and group dominance are used as an indicator of eutrophication and nutrient concentrations when evaluating ecological status (HELCOM, 2006; Fleming-Lehtinen, 2007).

\subsection{Data descriptions}

\subsubsection{In situ data}

The in situ dataset was acquired from the International Council for the Exploration of the Sea (ICES). It is built on the joint efforts of nine contracting parties within the Baltic region under the Cooperative Monitoring in the Baltic Marine Environment programme, known as the COMBINE marine monitoring programme established by the Baltic Marine Environment Protection Commission (HELCOM).

Briefly, in situ data such as salinity, nutrients and Chl-a were collected from 
numerous ship surveys at pre-defined sampling stations distributed in the open sea and coastal zones, with a time period spanning more than 20 years. During each field campaign, water samples were collected from the top water layer (0 or $1 \mathrm{~m}$ ) down to the deep water at an incremental depth of $5 \mathrm{~m}$. A standardised salinometer was used to determine the conductivity ratio of each sample, then the ratio obtained is converted into salinity based on the International Oceanographic Tables Vol.3 (UNESCO, 1981). Furthermore, the concentrations of dissolved oxygen and nutrients including silicate $(\mathrm{Si})$, nitrate $(\mathrm{N})$ and phosphate (P) concentrations were determined according to Grasshoff et al. (2009). Further information on the in situ sampling strategies can be found in HELCOM (2005)

\subsubsection{Satellite data}

MERIS imagery, provided by ESA and available at the Earthnet FTP site (ftp://eoa-up.eo.esa.int), was the basis of this study. This site contains the 3rd re-processed collection of Reduced Resolution (RR) level-1b (L1b) and level-2 (L2) datasets, with a spatial resolution of 1,200 $\mathrm{m} \times 1,200 \mathrm{~m}$ at the nadir. The entire dataset spans a time period of 10 years, available from late April 2002 until early April 2012. Due to the low sun elevation angle over the Baltic region during the morning in late autumn and early spring (generally from November to February), processed MERIS data is only available between March and October.

The entire set of the full swath L1b imagery (more than seven hundred images) was spatially extracted for the Baltic Sea, and radiometrically corrected using the L1b Radiometry Processor (Ver. 1.1.1) in the Basic ENVISAT AATSR and MERIS (BEAM Ver. 4.10.3.) Toolbox. A cloud probability product was then generated using the Cloud Probability Processor (Ver. 1.5.203), providing an improved cloud flag for cloud masking.

To minimise the potential errors arising from applying an atmospheric cor- 
rection, the Rayleigh corrected surface reflectance or Bottom of Rayleigh Reflectance (BRR) product was determined by removing the gaseous absorption, ozone and molecular Rayleigh scattering effects, which was calculated as:

$$
\rho_{B R R}=\rho_{T O A}^{*}-\rho_{R}
$$

where $\rho_{T O A}^{*}$ is the top-of-atmosphere (TOA) reflectance after the correction of ozone and gaseous absorption effects, and $\rho_{R}$ is the reflectance from the Rayleigh scattering. $\rho_{R}$ is calculated using the $6 \mathrm{~S}$ radiative transfer code (Vermote et al., 1997) within the BRR processor. Figure 2 shows the observed BRR spectra from four different type waters in the Baltic Sea.

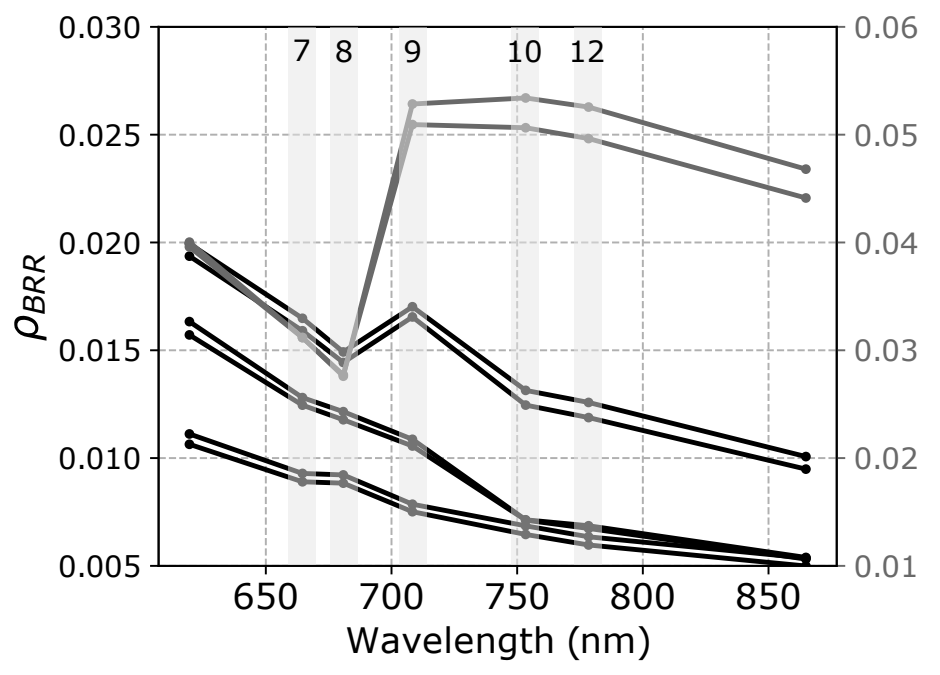

Figure 2: Rayleigh corrected surface reflectance of four different waters observed in the Baltic Sea.

The BRR dataset is then used to generate SPP images using the following 
equations:

$S P P=\sum_{i=1}^{3} \operatorname{Peak}_{i}\left(\lambda_{i}\right)$, if $P_{e a k_{i}}>0$

$\operatorname{Peak}_{1,2}\left(\lambda_{1,2}\right)=\rho_{B R R, \lambda_{1,2}}-\rho_{B R R, 664}-\left(\left(\rho_{B R R, 754}-\rho_{B R R, 664}\right) *\left(\lambda_{1,2}-664\right) /(754-664)\right)$

$\operatorname{Peak}_{3}\left(\lambda_{3}\right)=\rho_{B R R, \lambda_{3}}-\rho_{B R R, 709}-\left(\left(\rho_{B R R, 779}-\rho_{B R R, 709}\right) *\left(\lambda_{3}-709\right) /(779-709)\right)$

where $\lambda_{i}$ is the wavelength of MERIS bands at 681,709 and $754 \mathrm{~nm}$, respectively.

\subsection{Meteorological data}

To investigate the ecological response of phytoplankton assemblages to environmental perturbations, photosynthetically active radiation (PAR) and wind datasets were derived from the ERA reanalysis (Dee et al., 2011) from the European Centre for Medium-Range Weather Forecasts (ECMWF) website (http: //www.ecmwf.int). Monthly composites of daily mean wind speed $\left(\mathrm{m} \mathrm{s}^{-1}\right)$ are available at $10 \mathrm{~m}$ above the water surface with a spatial resolution of $0.125^{\circ} \times 0.125^{\circ}$, which are subsequently converted into wind stress $(\tau$, in a unit of $\mathrm{Pa}$ ) based on a function of wind speed, drag coefficient and boundary layer air density (Pond \& Pickard, 1983), such that

$$
\tau=\rho_{a} \times C_{D}|W| \times W
$$

where $\rho_{a}$ is the mean of air density equivalent to approximately $1.3 \mathrm{~kg} \mathrm{~m}^{-3}$; $W$ is the wind speed over the sea surface (for practical purposes, $10 \mathrm{~m}$ height wind speed, $W_{10}$, is mostly used); $C_{D}$ is the dimensionless drag coefficient varying with the wind speed (Yelland \& Taylor, 1996). 


$$
\begin{aligned}
& C_{D}=\left(0.29+\frac{3.1}{W_{10}}+\frac{7.7}{W_{10}^{2}}\right) \times 10^{-3}, \text { for } 3 \leq W_{10}<6\left(\mathrm{~m} \mathrm{~s}^{-1}\right) \\
& C_{D}=\left(0.6+0.07 \times W_{10}\right) \times 10^{-3}, \text { for } 6 \leq W_{10} \leq 26\left(\mathrm{~m} \mathrm{~s}^{-1}\right)
\end{aligned}
$$

The sea surface wind stress is an important factor in physical oceanography, as it drives the ocean circulation and controls the surface wave field generation and the wind-driven ocean surface current production (Wu, 1982; Yelland \& Taylor, 1996; Raitsos et al., 2006). Thus, wind stress is used to assess its influence on phytoplankton bloom dynamics.

The monthly composite of surface PAR within the ERA was generated at midnight (00:00) with an incrementing step of $12 \mathrm{~h}$, i.e. is an estimate of the midday (12:00) surface PAR (in $\mathrm{W} \mathrm{m}^{-2}$ ), and has a spatial resolution of $0.125^{\circ} \times$ $0.125^{\circ}$.

\section{Method for investigating phytoplankton blooms}

\subsection{Land, cloud and sea ice masking}

Land pixels, possessing high reflectance signals in the NIR region, can be confused with "surface scum" pixels for the approach applied. Thus, a land mask is needed before undertaking the investigation. To mask land pixels and divide the Baltic Sea into officially defined basins, a shapefile from the HELCOM Map and Data Service (http://maps.helcom.fi/website/mapservice/ index.html) was used. Furthermore, to reduce the occurrence of mixed landwater pixels, the land-water boundary was dilated towards the sea area by 1 pixel $(1.2 \mathrm{~km})$.

Suspended particles in turbid coastal regions can cause ambiguity within the derived signal, thus, the turbid regions of the Baltic Sea were further excluded 
and summer phytoplankton accumulations were only considered for the open regions of the Sea (Wasmund, 1997), which resulted in an $8 \%$ decrease in the total sea area. The final shapefile, see Figure 3, was used as a constant land mask and applied to the entire MERIS time series. The areas of each Baltic basin are listed in Table 1.

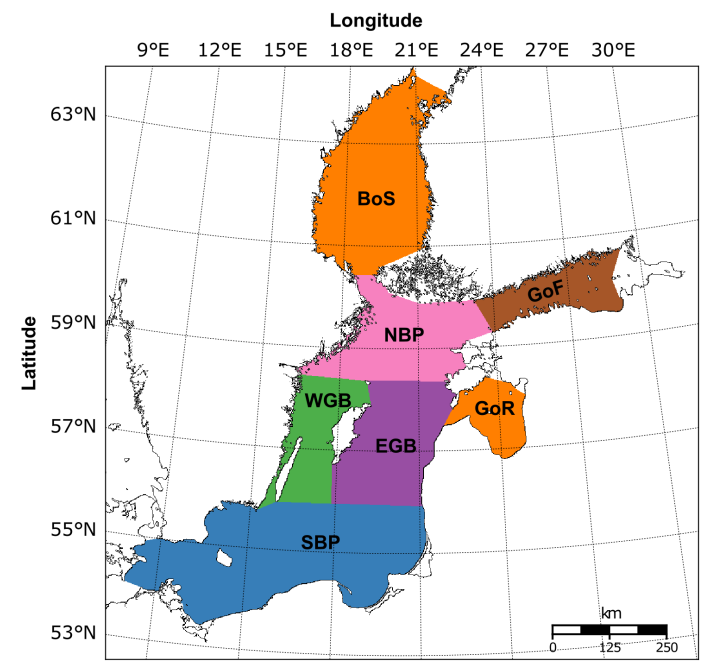

Figure 3: Study areas for investigating phytoplankton blooms in the Baltic Sea. The colour coded regions represent the division of Baltic basins defined by HELCOM, including BoS (1), GoF (2), GoR (3), NBP (4), WGB (5), EGB (6) and SBP (7). Land and turbid coastal regions are masked in white.

the two cloud masks together with the corresponding cloud probability product were used to mask all potential cloud pixels.

Apart from clouds, a few of the Baltic basins, such as GOF and GOR, are observed as having sea ice coverage during early spring. Compared with snow on land surfaces, snow and/or sea ice can be difficult to identify for sensors 
Table 1: The area of each Baltic basin calculated using the land mask file.

\begin{tabular}{cc}
\hline Basin Names & Total Area $\left(\mathbf{k m}^{2}\right)$ \\
\hline Bothnian Sea (BoS) & 63,062 \\
Gulf of Finland (GoF) & 20,642 \\
Gulf of Riga (GoR) & 14,550 \\
Northern Baltic Proper (NBP) & 41,364 \\
West Gotland Basin (WGB) & 25,678 \\
East Gotland Basin (EGB) & 41,534 \\
Southern Baltic Proper (SBP) & 90,255 \\
\hline
\end{tabular}

without short-wave infrared (SWIR $>1 \mu \mathrm{m}$ ) bands. An initial attempt using the MERIS Differential Snow Index (ATBD, 2011) considerably overestimated the Baltic Sea ice extent. Therefore, the MERIS L2 ice-haze flag was tested. Visual examination showed that this flag produced a reasonable sea ice mask. Hence the L2 ice-haze flag was applied to the entire image series.

Moreover, to avoid introducing bias from cloud and invalid pixels to phytoplankton bloom statistics, only satellite scenes containing more than $75 \%$ valid data (after the exclusion of cloud and invalid pixels) were selected. The number of valid MERIS images available in each Baltic basin is listed in Table 2. Note that MERIS imagery is only available between March and October due to the latitude of the study area as described previously in subsubsection 2.2.2.

\subsection{Bloom threshold and bloom segmentation}

Determining a global threshold for separating phytoplankton blooms from low to medium biomass waters is a crucial step in establishing an unbiased bloom record. An empirically defined threshold could lead to biases and/or uncertainties, thus a spatial gradient approach was used in this study to derive a bloom threshold statistically, see also Hu et al. (2010); Feng et al. (2012). 
Table 2: The number of valid MERIS images available in the Baltic basins and BoP as well as the whole Baltic Sea from 2002 to 2011.

\begin{tabular}{cccccccccc}
\hline Year & SBP & NBP & WGB & EGB & BoS & GoF & GoR & BoP & BalticSea \\
\hline 2002 & 17 & 34 & 31 & 29 & 33 & 30 & 34 & 20 & 18 \\
2003 & 33 & 47 & 47 & 50 & 35 & 30 & 38 & 35 & 23 \\
2004 & 26 & 41 & 40 & 41 & 31 & 30 & 35 & 29 & 26 \\
2005 & 36 & 43 & 49 & 47 & 39 & 33 & 43 & 40 & 31 \\
2006 & 38 & 43 & 46 & 41 & 40 & 35 & 38 & 34 & 32 \\
2007 & 29 & 40 & 39 & 45 & 39 & 39 & 44 & 33 & 22 \\
2008 & 34 & 45 & 47 & 45 & 53 & 36 & 42 & 34 & 34 \\
2009 & 28 & 50 & 55 & 47 & 42 & 37 & 44 & 32 & 24 \\
2010 & 22 & 38 & 31 & 37 & 31 & 31 & 30 & 28 & 20 \\
2011 & 28 & 42 & 43 & 40 & 36 & 20 & 33 & 31 & 21 \\
\hline
\end{tabular}

An alternative approach would be to use temporal derivatives that indicate phytoplankton growth rate, see Behrenfeld (2010).

The gradient images are generated from each SPP image (after the removal of land, cloud and sea ice), and each of the pixels within the gradient image is defined as the SPP difference from the eight adjacent pixels in a $3 \times 3$ window, such that:

$$
\text { gradient }=\sqrt{\frac{1}{8} \sum_{i=1}^{8}\left(\frac{d y_{i}}{d x_{i}}\right)^{2}}
$$

where $d y_{i}$ and $d x_{i}$ are the variation in the SPP value and pixel location for the 8 neighbouring pixels.

At the boundary between blooms and the background water, the SPP value is known to have the sharpest change that is represented by the maximum value in the corresponding gradient image. Hence, the bloom-water boundary can be outlined by the pixels that have the highest SPP gradient. However, the pixels having high gradient values may also describe the boundary between 
phytoplankton blooms and surface scums, as scum pixels have higher SPP values than bloom pixels. In order to avoid the confusion between the two boundary types (i.e. background-bloom and bloom-scum), a threshold of SPP $>0.01$ is used to exclude the pixels from surface scum and/or floating algae. As for the remaining pixels in the gradient image, a histogram is generated to determine the maximum gradient values. Therefore, the maximum gradient is not determined from a single pixel but from a group of pixels that outline the boundary between blooms and the background water. Then, the mean of SPP values having the maximum gradients is used as the threshold to identify bloom pixels in the SPP imagery. This method is applied to the entire SPP image series to calculate all individual thresholds.

From a visual examination, the results indicated that this method worked well in most cases, except for the case where patchy blooms are observed and there are limited pixels within the histogram; see also (Hu et al., 2010). Therefore, instead of using an image-dependent threshold, all the individual thresholds are used to generate a histogram, from which an overall bloom threshold is determined as the mean minus one and half standard deviations, see Figure 4.

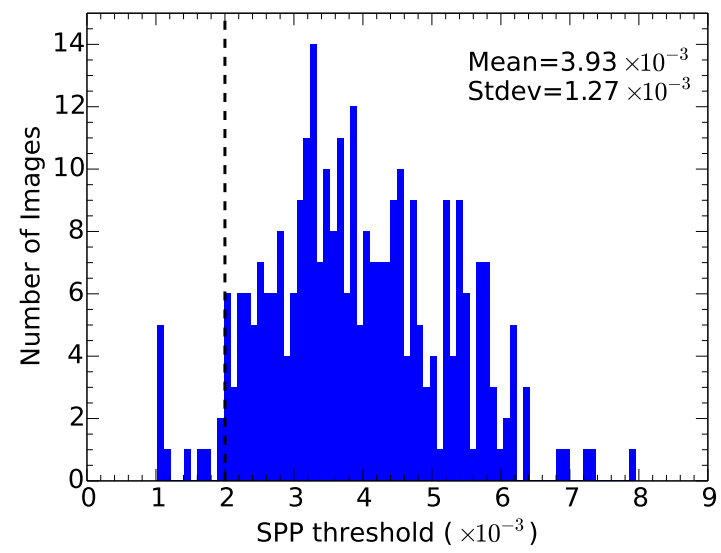

Figure 4: Histogram of bloom thresholds determined from the entire SPP time series. The dashed vertical line represents the location of the global bloom threshold (0.002) that is calculated as the mean minus one and half standard deviations 

set to 0.002 , which is equivalent to a Chl-a concentration of approximately $6 \mathrm{mg}$ ${ }_{287} \mathrm{~m}^{-3}$ when the established SPP-Chl-a algorithm is applied; this concentration 288 is slightly higher than the commonly used threshold $\left(5 \mathrm{mg} \mathrm{m}^{-3}\right)$ defined by 289 (Kutser et al., 2006). Hence, unless otherwise noted, a SPP threshold of 0.002 290 was used for the phytoplankton bloom identification. The bloom identification examples are presented in Figure 5, where the detected blooms are outlined with 292 black lines. 


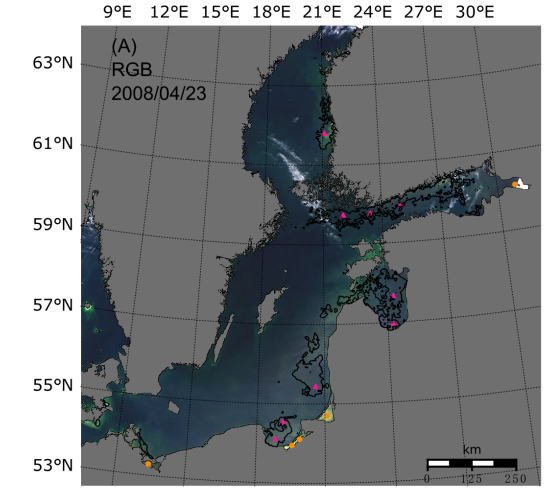

$9^{\circ} \mathrm{E} \quad 12^{\circ} \mathrm{E} \quad 15^{\circ} \mathrm{E} \quad 18^{\circ} \mathrm{E} 21^{\circ} \mathrm{E} \quad 24^{\circ} \mathrm{E} \quad 27^{\circ} \mathrm{E} \quad 30^{\circ} \mathrm{E}$
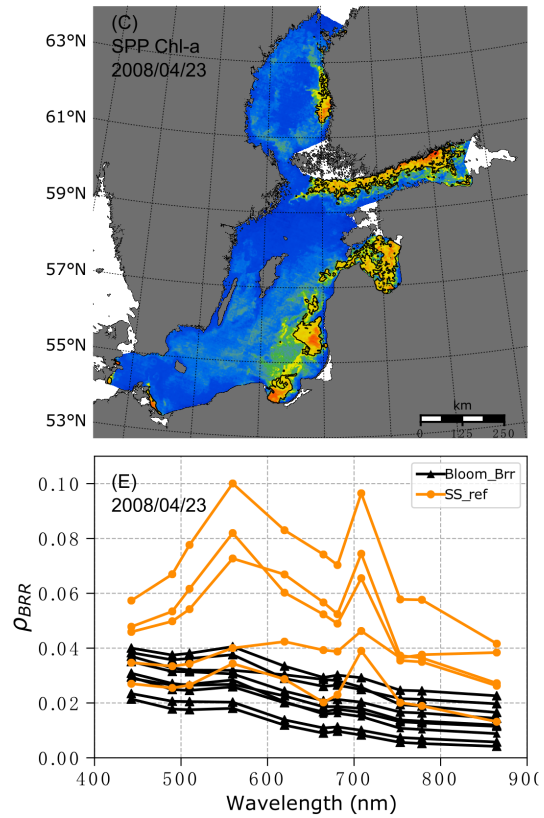

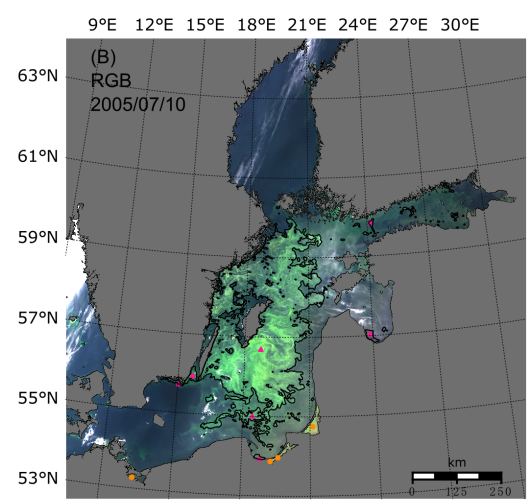

$9^{\circ} \mathrm{E} \quad 12^{\circ} \mathrm{E} \quad 15^{\circ} \mathrm{E} 18^{\circ} \mathrm{E} 21^{\circ} \mathrm{E} 24^{\circ} \mathrm{E} 27^{\circ} \mathrm{E} \quad 3^{\circ} \mathrm{E}$
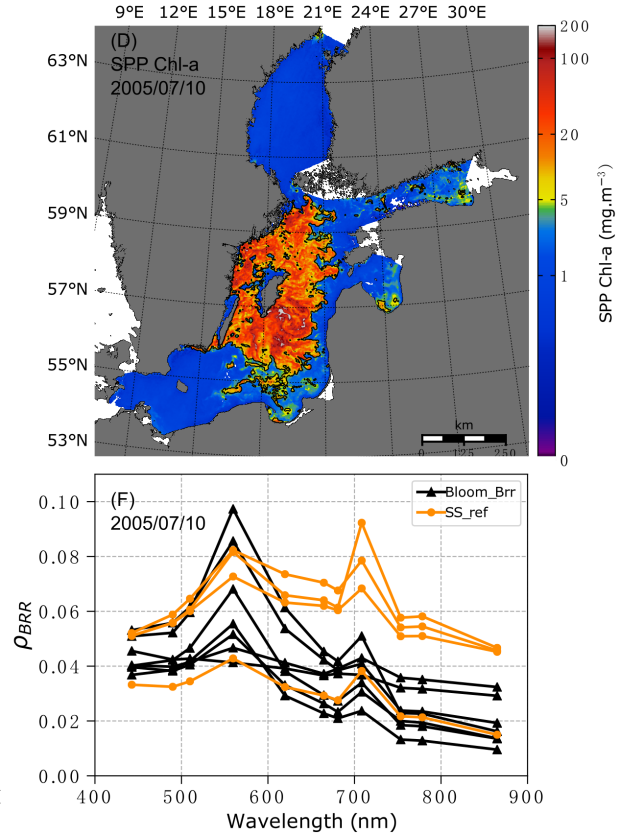

Figure 5: Application of the phytoplankton bloom detection approach to the Baltic Sea on 23rd April 2008 and 10th July 2005 and the BRR spectra extracted from blooms and turbid waters; Panel A-B show the corresponding true colour composites derived from MERIS bands 7 (red), 5 (green), 2 (blue). Panel C-D are the SPP Chl-a maps, where black lines outline the detected bloom extents identified using the global SPP threshold $(\geq 0.002)$. Panel E-F show the BRR spectra derived from the artificially defined sampling points that were located within bloom areas and turbid regions and are shown as purple and orange dots in Panel A and B, the spectra from bloom waters (Bloom_Brr) and turbid regions (SS_ref) are demonstrated in black and orange lines, respectively. 
The SPP images are then geo-referenced to a standard Albers equal area projection with a spatial resolution of $1.2 \mathrm{~km}$. The phytoplankton bloom coverage area is then calculated from the total number of bloom pixels and pixel size.

Thus, the processing chain can be expressed as following steps:

1. Mask land, cloud and sea ice in each SPP image using the methods described in subsection 3.1.

2. Generate gradient images from the entire time series and determine the individual threshold from the gradient image. Then, derive the global threshold from all individual thresholds, as described in subsection 3.2.

3. Determine the total number of bloom pixels, and calculate the bloom areas.

\subsection{Phytoplankton variations and environmental perturbations}

To investigate the interannual variation of phytoplankton assemblages and in the consideration of the wind effect on the surface bloom formation, monthly maximum SPP composites were derived from the entire time series by taking the maximum SPP values at each pixel from the daily images within a given month.

The monthly maximum composites provide cloud-free imagery and were used for estimating total phytoplankton intensity and cumulative bloom areas through different seasons. In particular, the total intensity was defined as the sum of all SPP values within each Baltic segment, and the cumulative area was determined by calculating the total number of pixels that have SPP values greater than the global bloom threshold. To better demonstrate the variation in phytoplankton biomass, all phytoplankton intensities indicated by SPP values were converted into phytoplankton abundance (in Chl-a concentration) using the 
previously established relationship between SPP and Chl-a. Then, phytoplankton abundance was used to investigate ecological responses of phytoplankton assemblages to environmental perturbations.

To assess the ecological response of phytoplankton assemblages and identify potential summer bloom drivers, physical, hydrological alongside meteorological variables were examined. Specifically, monthly mean sea surface temperate (SST), N and P concentrations were taken within the water column from 0 to 20 $\mathrm{m}$ in each Baltic basin. Considering the surface layer $\mathrm{P}$ left after spring blooms has positive effects on the summer bloom formation, thus $\mathrm{P}$ concentration measured during May and June was included. Additionally, it is suggested that excess phosphate (eDIP) available in spring months is a key factor favouring the summer bloom development in the Baltic Sea (Kiirikki et al., 2001; Janssen et al., 2004), thus the surface layer eDIP is acquired under the assumption that nutrient uptake occurs at the Redfield ratio of $\mathrm{N}_{16}: \mathrm{P}_{1}$ that is $\mathrm{P}-\mathrm{N} / 16$. All these variables were then processed to obtain basin-specific datasets. It is worth noting that the in situ data collected from GoR were significantly lacking, which restricted the data interpretation and statistical analysis. Thus the results related to GoR presented hereafter were just included for the comparison and reference purposes only, unless otherwise noted.

The candidate predictor variables used in this study were $\mathrm{P}$ measured in May and June, eDIP observed during February and March alongside SST, PAR, wind stress acquired in July and August. Boosted Regression Trees (BRTs) were first utilised to evaluate the relative variable importance for each candidate predictor listed above (Friedman \& Meulman, 2003; Elith et al., 2008). For the independent set of predictor variables, generalised additive models (GAMs) were then used to investigate the relationship between summer bloom abundance and each predictor variable for the major Baltic basins. 


\section{Results}

\subsection{Spatial and temporal extent of phytoplankton blooms}

It can be seen from Figure 6 that phytoplankton bloom coverage derived from the daily images shows apparent seasonal cycles, with the maximum extent being observed in April-May and July-August during 2002-2011. In addition, there is an apparent variation in summer bloom sizes detected over the whole Baltic Sea and four central Baltic basins between 2002-2004 and 2006-2011, with substantial summer blooms being observed in 2005 . To better demonstrate the spatial variation, $25 \%$ bloom area coverage of the segment's total area is used to define the level of significance. In particular, more than 10 significant summer blooms were observed in the central regions (WGB, EGB and NBP) during July between 2002 and 2005, whereas after 2005 the significant summer blooms rarely occurred in these regions. As for spring blooms, the daily coverage was generally below the significant level in all central segments, with higher extents being frequently appeared in SBP.

Compared with the central Baltic basins, the observed summer bloom extents in GoF and GoR rarely exceeded 25\% of the entire areas between 2002 and 2011; whereas significant spring blooms appeared annually, with frequent and persistent occurrences being detected after 2003, especially in GoR. In particular, only two significant summer blooms (2002 and 2007) were detected in GoF, with a substantial area coverage of up to $15,000 \mathrm{~km}^{2}$ measured in 2002; whereas in GoR, summer blooms never exceeded the significant level except 2005 and 2010. During spring seasons, the highest bloom extent was generally observed in later April and May, with a significant bloom duration of up to $11( \pm 11)$ days detected in GoR in 2007 and 2009, and $7( \pm 7)$ days in GoF in 2004. Despite no significant summer blooms occurring in GoR, extensive spring blooms covering more than $50 \%$ of the entire gulf were detected every year between 2002 and 


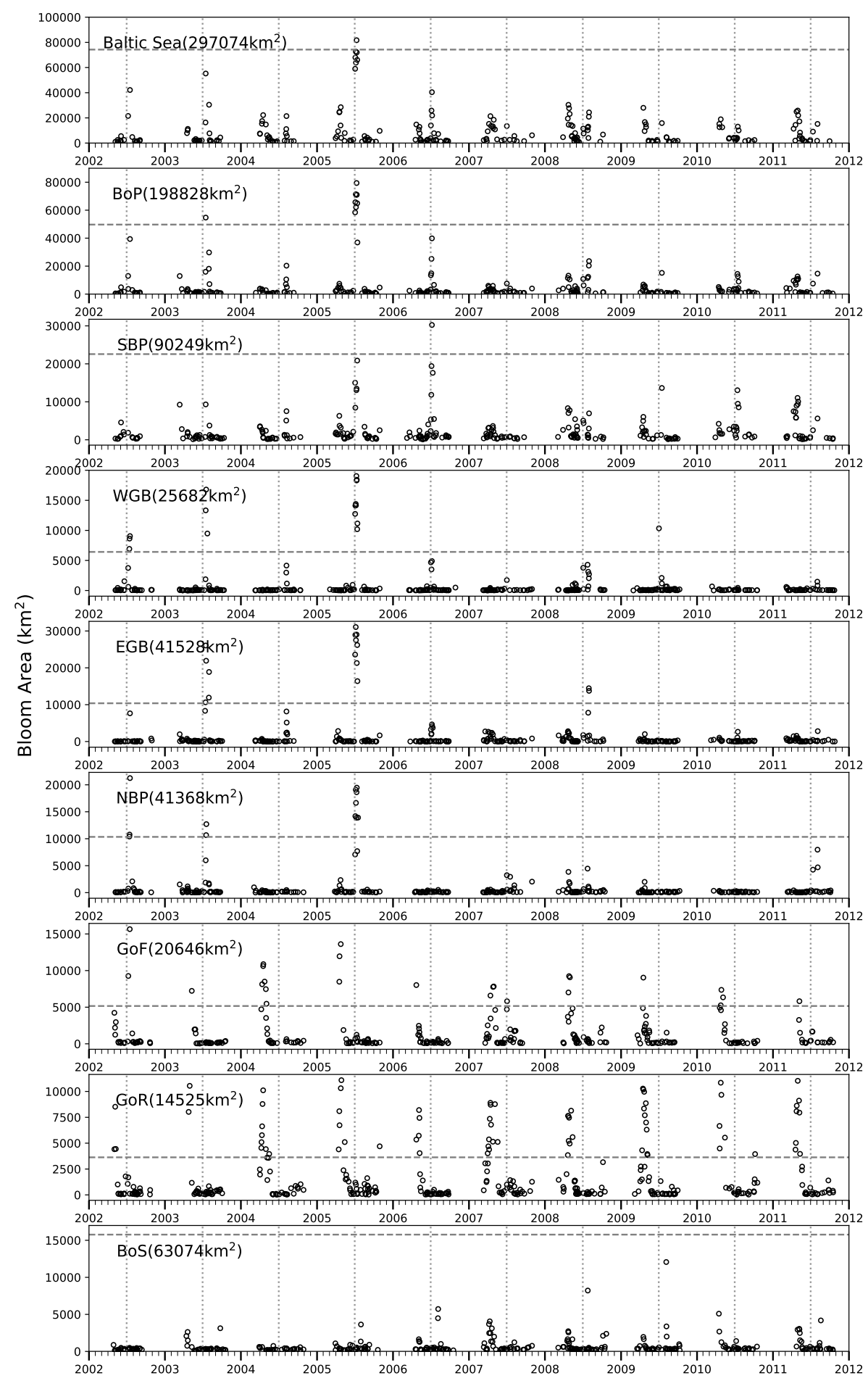

Figure 6: Phytoplankton bloom coverage derived from the daily SPP images for each Baltic basin. The horizontal dashed line on each panel denotes a threshold of $25 \%$ of the total segment area and vertical dashed lines indicate July of each year. 
2011; whereas, such extensive spring blooms were only observed in 2004 and 2005 in GoF.

As for the northernmost segment, BoS never had a significant spring nor a summer bloom over the period studied. The seasonal succession of phytoplankton blooms was less apparent, and the bloom size was also not as considerable as for other Baltic basins. Although blooms were observed in both spring and summer seasons, the maximum extent was generally less than $8,000 \mathrm{~km}^{2}$ between 2002 and 2011. 2009 was an exceptional year with a summer bloom extent exceeding $16 \%\left(10,000 \mathrm{~km}^{2}\right)$ of the entire segment area. In addition, the timing of summer blooms was generally late in this region.

\subsection{Timing of summer phytoplankton blooms}

Figure 7 shows the date (day of the year) of the first appearance of summer blooms observed during July-August over the past decade. Due to the discontinuous nature of valid MERIS images (approximately one cloud-free image per week is available for each basin during the summer), the spatial distribution of the summer bloom timing may appear more variable than it is in reality. 

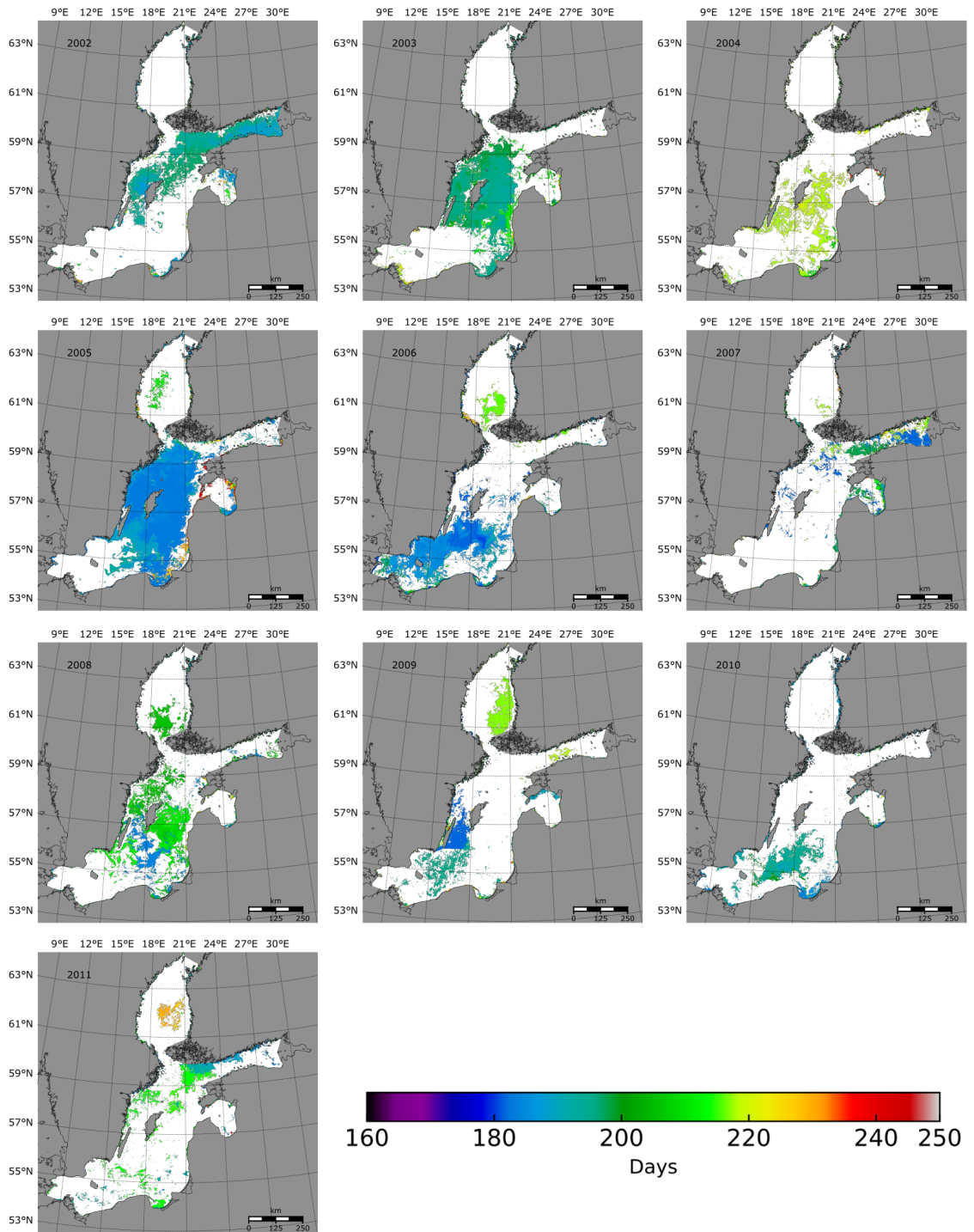

Figure 7: The timing of summer bloom occurrence observed during July-August between 2002 and 2011 in the Baltic Sea. For each location, the first day when the bloom occurred is colour-coded and the white denotes no blooms detected. 
As can be seen from Figure 7, there were two early summer occurrences of blooms observed in BoP between 2005 and 2006, where extensive surface accumulations dominated nearly half the central region in the first week of July; for the remaining years, BoP summer blooms were generally observed in the second half of July or in August. Two late summer blooms observed in 2004 and 2011 were particularly noticeable, with the extensive surface accumulations dominating the central region in the first week of August. The spatial distributions of summer bloom timing in GoF and GoR were rather patchy, but the southeast region of these two gulfs generally showed earlier summer blooms. As for summer bloom timing in BoS, it was generally in late July and August.

\subsection{Phytoplankton dynamics and cumulative bloom areas}

Figure 8 shows the spatial distribution of summer (July-August) phytoplankton abundance retrieved between 2002 and 2011. Considering the summer blooms typically occurred in the central Baltic region (i.e. BoP), the integrated area of the four central basins was used for the analysis. 

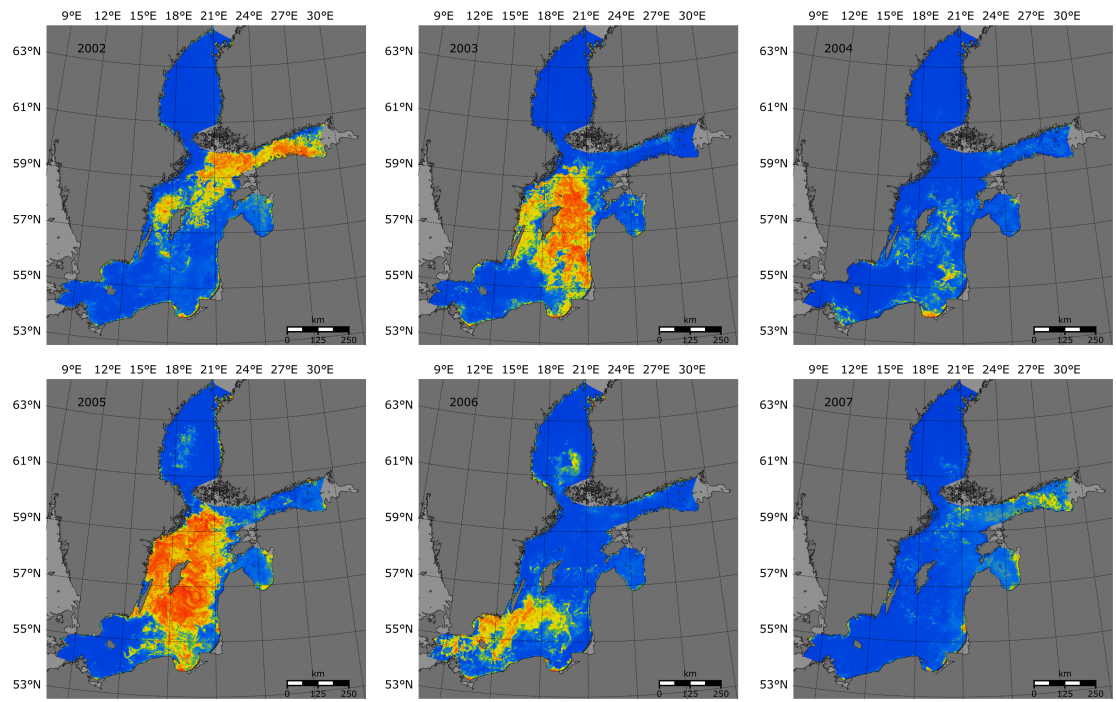

$9^{\circ} \mathrm{E} \quad 12^{\circ} \mathrm{E} \quad 15^{\circ} \mathrm{E} \quad 18^{\circ} \mathrm{E} 21^{\circ} \mathrm{E} 24^{\circ} \mathrm{E} 27^{\circ} \mathrm{E} 30^{\circ} \mathrm{E}$

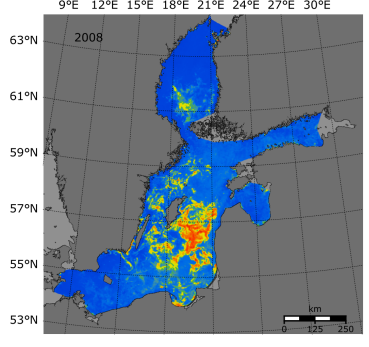

$9^{\circ} \mathrm{E} \quad 12^{\circ} \mathrm{E} 15^{\circ} \mathrm{E} 18^{\circ} \mathrm{E} 21^{\circ} \mathrm{E} 24^{\circ} \mathrm{E} 27^{\circ} \mathrm{E} 30^{\circ} \mathrm{E}$

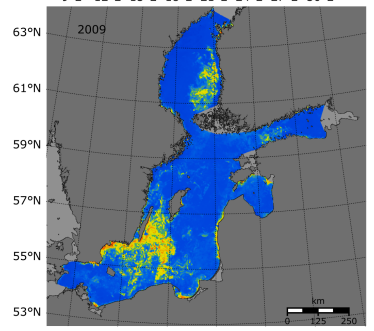

$9^{\circ} \mathrm{E} 12^{\circ} \mathrm{E} \quad 15^{\circ} \mathrm{E} 18^{\circ} \mathrm{E} 21^{\circ} \mathrm{E} 24^{\circ} \mathrm{E} 27^{\circ} \mathrm{E} 30^{\circ} \mathrm{E}$
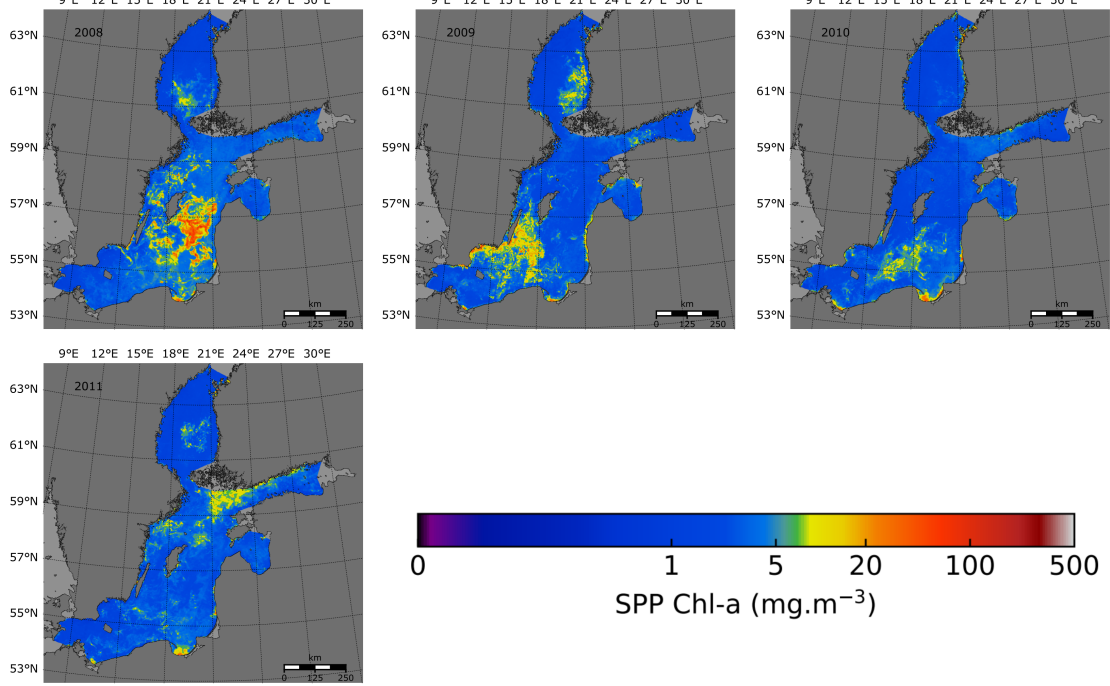

Figure 8: The mean of July-August maximum Chl-a composites produced for the Baltic Sea between 2002 and 2011. 
The result, presented in Figure 9, shows the total phytoplankton abundance and cumulative bloom area determined in each basin between 2002 and 2011 . It can be clearly seen that the phytoplankton abundance showed an overall seasonal cycle, increasing from March, peaking in April-May, and then decreasing until summer blooms appearing in July-August. The lowest phytoplankton intensity was usually observed in winter, after the decline of the summer blooms during the autumn. As for BoP, the summer phytoplankton intensity was much higher than that measured in spring, with two substantial blooms observed in 2003 and 2005. Whereas in GoF and GoR, the spring measured phytoplankton abundance was generally higher than the summer abundance. An exceptional event was detected in GoF during 2002, where the summer bloom reached the highest level over the 10-year period. As for BoS, the seasonal succession of phytoplankton intensity became clearer after 2007, with the maximum phytoplankton abundance generally appearing in April and August. An extensive summer bloom event, having a total coverage of more than $10000 \mathrm{~km}^{2}$, was observed in 2009. 


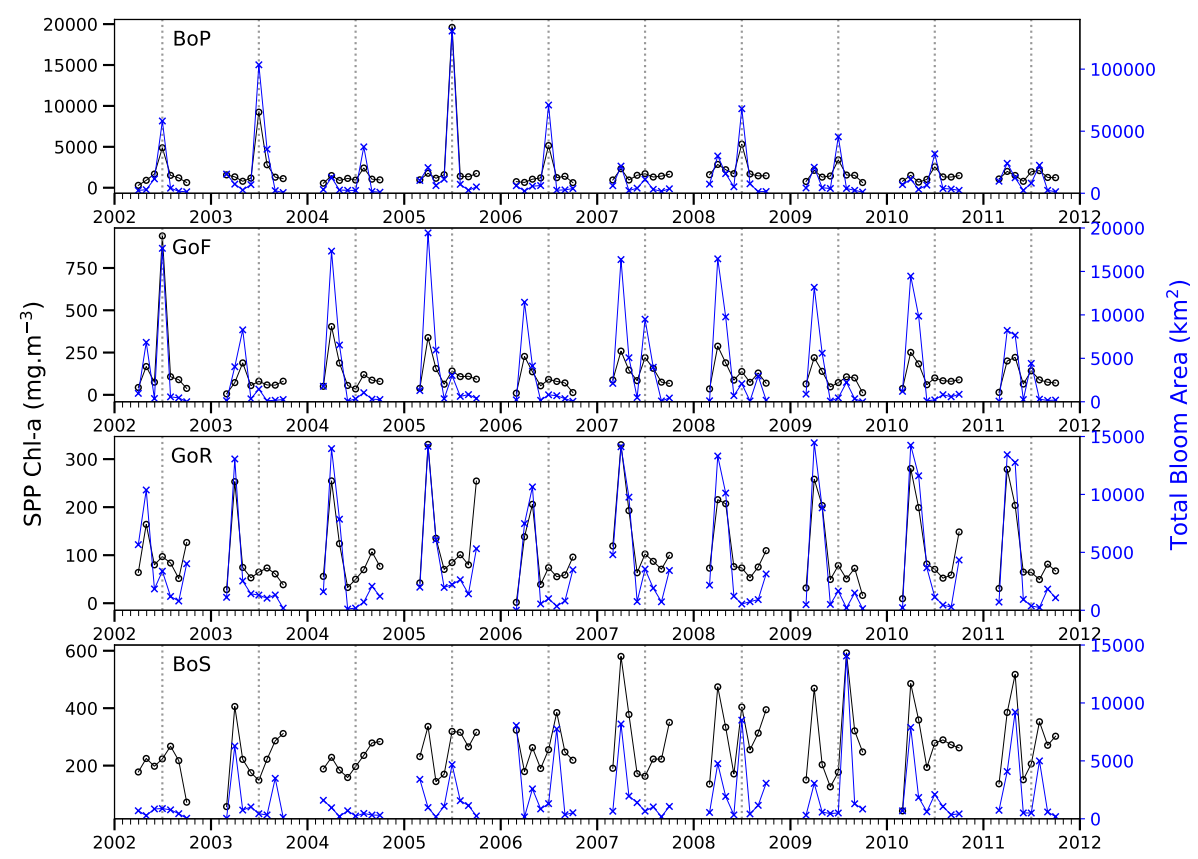

Figure 9: Time series of total phytoplankton abundance (black line) and total bloom areas (blue line) derived from monthly maximum Chl-a composites generated between 2002 and 2011. The dashed grid lines on each panel denote July of each year. 


\subsection{Environmental forcing}

The statistical analysis of environmental factors indicates that several potential predictor variables were strongly correlated with each other (Spearman rank order correlation coefficient: $\left.\left|\mathrm{r}_{s}\right|>0.55\right)$. To avoid the problem in modelling, the variable that was highly correlated with other parameters was excluded, and only the independent set of potential candidates was retained for the investigation.

In the central Baltic region of BoP, March eDIP showed a strong positive correlation with May-June (early summer) P concentration $\left(\mathrm{r}_{s}=0.78, \mathrm{p}<0.008\right)$, and July-August (summer) PAR was highly correlated with summer SST $\left(\mathrm{r}_{s}=0.6\right.$, $\mathrm{p}<0.067)$ and wind stress $\left(\mathrm{r}_{s}=-0.65, \mathrm{p}<0.05\right)$, thus these two variables were excluded. The result from BRTs shows that February eDIP (Feb_eDIP) had the highest relative influence (38.9\% of the total deviance explained) on summer bloom abundance, followed by summer SST (28.2\%). Of all potential predictor variables considered, early summer $\mathrm{P}$ and summer wind stress were shown having similar impact (14.5-18.4\%) on summer bloom abundance. GAM established using the four predictor variables indicates that $95.9 \%$ of the variation in summer bloom abundance was interpreted, with mean absolute error (MAE) of $381.7 \mathrm{mg}^{-3}$. Panel A, Figure 10 indicates the partial dependency of the summer mean bloom abundance on Feb_eDIP. It can be seen that the bloom abundance increased exponentially with Feb_eDIP, and within the eDIP range from 0.35 to $0.5 \mathrm{umol} / \mathrm{L}$, up to eight blooms were observed with the total abundance between 1505 and $5800 \mathrm{mg} \mathrm{m}^{-3}$. Panel B, Figure 10 shows that summer bloom abundance responded to Jul-Aug SST nonlinearly, it increased as increasing SST within the range from 15.4 to $16.5 \mathrm{deg} \mathrm{C}$, but remained relative stable above this range. As for May-Jun P (Panel C, Figure 10), the model shows that increasing $\mathrm{P}$ amount from 0.11 to $0.25 \mathrm{umol} / \mathrm{L}$ only led bloom abundance to increase 927 
$\mathrm{mg}^{-3}$. Panel D, Figure 10 indicates that low wind stress ranging from 0.04 to 0.05 had a weak positive impact on bloom abundance, whereas for wind stress greater than $0.055 \mathrm{~Pa}$, its negative influence on the bloom abundance became apparent.

In GoF, Feb_eDIP showed a positive correlation with May-June $\mathrm{P}\left(\mathrm{r}_{s}=0.65\right.$, $\mathrm{p}<0.05)$, and summer wind stress was strongly correlated with SST $\left(\mathrm{r}_{s}=-0.76\right.$, $\mathrm{p}<0.02)$ and PAR $\left(\mathrm{r}_{s}=-0.54, \mathrm{p}<0.2\right)$ measured in the same season, hence these two candidate variables were excluded. The BRTs ranking indicates that Mar_eDIP had the highest relative impact on summer bloom abundance, with $46.2 \%$ of the total deviance explained. The influence of May-Jun P on the bloom abundance was moderate $(27.6 \%)$, and summer SST and PAR showed similar low impact (11.7-14.5\%). Combining the four independent predictor variables to build GAM, the result shows that $72.3 \%$ of the variation in GoF summer bloom abundance is explained $\left(\mathrm{MAE}=42.3 \mathrm{mg} \mathrm{m}^{-3}\right)$. As shown in Panel E, Figure 10 that summer mean bloom abundance exhibited an approximate linear relationship with increasing Mar_eDIP, and within the Mar_eDIP range from 0.17 to $0.72 \mathrm{umol} / \mathrm{L}$, up to nine blooms were observed, having a mean Chl-a concentration of $147 \mathrm{mg} \mathrm{m}^{-3}$. For the early summer P (see Panel F, Figure 10), a positive relationship with bloom abundance was identified when the surface concentration was below $0.25 \mathrm{umol} / \mathrm{L}$, and above which a negative impact was detected. As for summer PAR (Panel G, Figure 10), it had a positive relationship with increasing mean bloom abundance, a similar pattern was also found in JulyAugust SST (Panel H, Figure 10), where the bloom abundance increased with increasing SST until it reached $16.6 \mathrm{deg}$ C.

For the northernmost region of BoS, the statistical analysis indicated that July-August wind stress was strongly correlated with summer $\operatorname{SST}\left(\mathrm{r}_{s}=0.58\right.$, $\mathrm{p}<0.09)$ and PAR $\left(\mathrm{r}_{s}=-0.5, \mathrm{p}<0.2\right)$. Although February and March eDIP were 
both independent with other candidate variables, our initial modelling test showed that the model incorporating Mar_eDIP had a better performance over that incorporating Feb_eDIP $\left(\mathrm{R}^{2}=0.69, \mathrm{MAE}=27.3 \mathrm{mg} \mathrm{m}^{-3}\right)$, thus Mar_eDIP was used. The associated result of Feb_eDIP is not presented here. Particularly, BRTs ranking shows that Mar_eDIP had the highest relative importance $(33.1 \%)$ over other predictor variables, and the relative impacts of July-August SST, May-June P and summer PAR on the mean bloom abundance were $26.2 \%$, $25.3 \%$ and $15.5 \%$, respectively. The result from GAM indicates that $82.7 \%$ of the variance in the summer mean bloom abundance was explained by the four predictor variables, with the MAE of $16.2 \mathrm{mg} \mathrm{m}^{-3}$. Panel I, Figure 10 shows the partial dependency of the bloom abundance on Mar_eDIP, where the bloom abundance increased along with March eDIP although it was deficient (less than zero) in the surface layer. As for summer SST, it exhibited a similar pattern as that detected for BoP and GoF, where the bloom abundance increased nonlinearly with increasing SST until the temperature reached $15 \operatorname{deg} \mathrm{C}$ (lower than that measured in the other two regions). Panel K, Figure 10 indicates the negative relationship between the mean bloom abundance and May-June P, where up to 8 blooms were observed within the $\mathrm{P}$ range from 0.02 to $0.05 \mathrm{umol} / \mathrm{L}$. As for summer PAR, the model showed that the mean bloom abundance decreased slowly with increasing PAR within the range from 359 to $407 \mathrm{~W} \mathrm{~m}^{-2}$.

The results shown above demonstrate that spring eDIP is the key factor influencing summer mean bloom abundance in the major Baltic basins. 

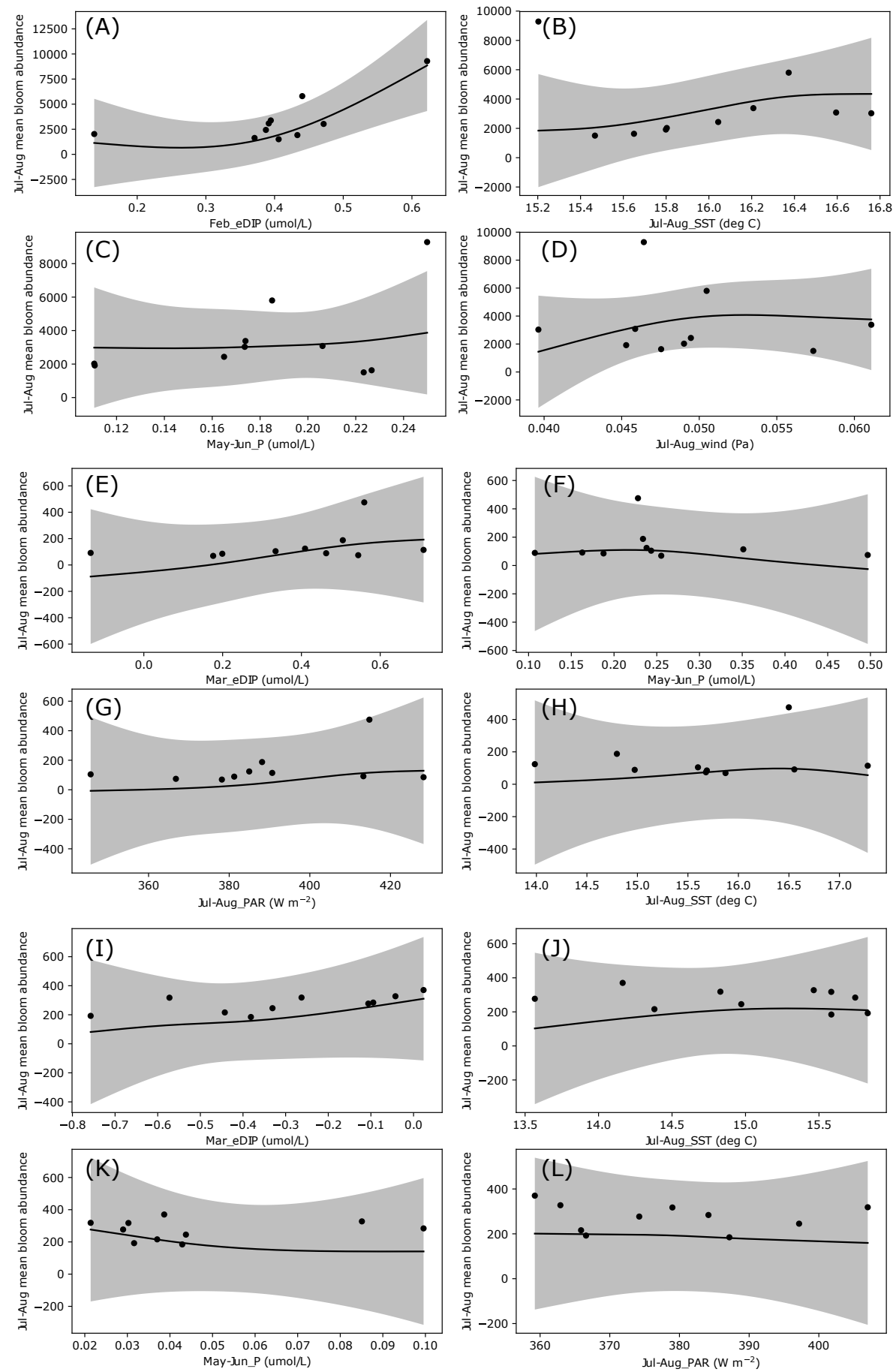

Figure 10: GAM partial dependency plots demonstrate the relationships between summer mean bloom abundance and independent predictor variables for the three Baltic basins. Panel A-D illustrate the model $\left(\mathrm{R}^{2}=0.96\right)$ for BoP, which incorporates Feb_eDIP (A), Jul-Aug_SST (B), May-Jun_P (C) and Jul-Aug_wind (D); 32 anel E-H show the modelling result $\left(\mathrm{R}^{2}=0.72\right)$ for GoF that incorporates Mar_eDIP, May-Jun_P, Jul-Aug_PAR and SST; Panel I-L present the result $\left(\mathrm{R}^{2}=0.83\right)$ for BoS, incorporating Mar_eDIP, Jul-Aug_SST, May-Jun_P and JulAug_PAR; The connected line is the spline, black dots represent the raw data, and gray shadow indicates the $95 \%$ confidence interval. 


\section{Discussion}

\subsection{Assessment of retrieved bloom extents}

The presented bloom record was derived using the SPP approach, which was originally designed for estimating phytoplankton abundances in the Baltic Sea (Zhang et al., 2017). Considering the spectral similarity between phytoplankton and suspended particles observable at $\sim 700 \mathrm{~nm}$, the accuracy of bloom observations primarily depends on whether surface phytoplankton accumulations are solely quantified for each image, i.e. false detections in turbid productive waters that were excluded as shown in Figure 3. This could have led to a decrease in the total bloom size detected, but should not affect the overall conclusions. Ideally, the retrieved bloom spatial extent should be validated using concurrent ground truth data. Unfortunately, this is often unfeasible due to limited spatial and temporal distribution of field survey data and the patchy nature of bloom distributions. Therefore, a number of sampling points from the identified bloom areas together with points located within the turbid lagoons are artificially defined to demonstrate the accuracy, see Panel A-B, Figure 5 for the point locations.

Panel E-F Figure 5 present the extracted BRR spectra collected from two bloom seasons. Generally, the BRR from the detected spring bloom waters is characterised by observable reflectance peaks at $681 \mathrm{~nm}$, with a lowered signal at $709 \mathrm{~nm}$, and the spectral shape differs significantly from the concurrent reflectance observed in turbid lagoons. As for the spectra from summer bloom waters, the $681 \mathrm{~nm}$ reflectance troughs and $709 \mathrm{~nm}$ reflectance peaks are both present. Although summer blooms and suspended particles have similar spectral features, it is known that only surface accumulations of phytoplankton in the open region can produce such spectral features, thus it excludes the possibility that the identified blooms are turbid waters. This result agrees with previous study where these two reflectance types were categorised into eukaryote and 
cyanobacteria dominant waters (Zhang et al., 2017).

\subsection{The dominance of phytoplankton groups from the time series}

The dominant phytoplankton groups in different seasons have already been identified by previous researchers (Wasmund \& Uhlig, 2003; Smayda \& Trainer, 2010; Janssen et al., 2004; Kahru et al., 2007). The phytoplankton abundance and bloom spatial extent retrieved during March should be attributed to the increased biomass of diatom groups. Between April and June, when diatoms were gradually outcompeted by dinoflagellates, the occurrence of the first peak of the detected abundance and bloom extent should be regarded as dinoflagellatedominated phytoplankton assemblages. When optimal weather conditions appeared during summer months, the proliferation of nitrogen-fixing and bloomforming cyanobacteria species in the surface layer resulted in the dominance shifting from dinoflagellates to cyanobacteria. Thus the abundance and bloom extent peaks observed in July and August should be attributed to cyanobacteria species. The subsequent decay of summer cyanobacteria blooms was followed by the outbreak of autumn diatom blooms in the Baltic basins, excluding BoS. This seasonal cycle of phytoplankton blooms was apparent in the time series retrieved between 2002 and 2011, see Figure 9.

In addition to the seasonal cycle of phytoplankton blooms, the preference of different phytoplankton groups also can be used to identify the group dominance. Particularly, diatoms generally prefer high salinity waters, and bloom-forming cyanobacteria species are known to be ubiquitous in low saline regions. As can be seen from Figure 9, spring phytoplankton intensity reached the maximum level during March 2003 and 2006 in BoP, whereas the higher values were measured during April-May in the less saline regions of GoF and GoR, indicating that BoP was more likely to have diatom blooms than the Baltic gulfs. 


\subsection{Driving factors of summer blooms}

Cyanobacteria ecological studies have identified several factors affecting the appearance of summer blooms (Sellner, 1997; Wasmund, 1997). The preference of low saline waters confines the spatial distribution of bloom-forming cyanobacteria species to low saline regions, making them absent in the transition zone (i.e. Kattegat and Danish Straits). The increased water temperature and high availability of solar irradiance provide optimal conditions for cyanobacteria to reach the highest growth rate during the early summer. The subsequent appearance of a highly stratified water column and low wind weather conditions further promotes cyanobacteria assemblages to accumulate as surface blooms during the summer months. These theories have been partly confirmed in this study, except BoS where the impact of summer PAR on the bloom abundance was relatively low see Figure 10L. Compared with hydrological factors, favorable PAR, SST and wind conditions are likely to be prerequisites rather than determining factors for phytoplankton assemblages to reach the bloom-level biomass. Additionally, Wasmund et al. (1998) suggested that the light penetration depth and the vertical distribution of phytoplankton in the water column are also important aspects in controlling the formation of summer surface blooms.

Regarding the nutrient loading, the low N:P ratio resulting from the high concentration of $\mathrm{P}$ in the hypoxic and/or anoxic bottom layer (Kononen, 1992) has traditionally been considered as a key factor governing the summer bloom development (Niemi, 1979). Whilst Wasmund (1997) suggested that a low N:P ratio was a prerequisite rather than a trigger. This theory was later confirmed by numerical models (Kiirikki et al., 2001; Lilover \& Stips, 2008), suggesting the surface layer eDIP availability is more important than the $\mathrm{N}: \mathrm{P}$ ratio in controlling the summer bloom formation. Indeed, as diazotrophic filamentous cyanobacteria are capable of fixing atmospheric nitrogen, the $\mathrm{P}$ availability is 
the major limiting factor for the proliferation of summer blooms. As shown in Figure 10C, the May-June surface layer $\mathrm{P}$ was identified as one of the top three important variables, and positively correlated with the July-August bloom abundance in BoP. A similar relationship was also observed in GoF when the $\mathrm{P}$ was within the range from 0.1 to $0.25 \mathrm{umol} / \mathrm{L}$.

Compared with the P loading, summer mean bloom abundances measured in the three Baltic basins were better interpreted by spring eDIP, see Figure $10 \mathrm{~A}, \mathrm{E}, \mathrm{I}$. This is because diatom and dinoflagellate assemblages generally consume winter-spring nutrients at the Redfield ratio of $\mathrm{N}_{16}: \mathrm{P}_{1}$ in spring, and their growth stops when one of the nutrients is depleted (either N or P) (Janssen et al., 2004). Thus, the availability of winter-spring nutrients directly affects the amount of eDIP left for summer cyanobacteria. As demonstrated in Figure 10 that eDIP measured either in February or March was always has the highest relative importance, and its positive effect on the bloom abundance was much clearer than other predictor variables investigated. Due to the limited number of summer blooms derived from the MERIS data archive, no attempt is made for any further investigation. Fortunately, the recently launched Sentinel-3 OLCI will enable the SPP algorithm to be transferred for retrieving the bloom abundance. This will not only allow the bloom record to be extended, but also be beneficial to a better understanding of other bloom drivers.

\section{Conclusions}

This study has presented phytoplankton phenology features for the major Baltic basins using the 10-year MERIS archive and the SPP algorithm for the time period from 2002 to 2011. The spatial variability of phytoplankton blooms and timing observed over the surface layer has been demonstrated, alongside the temporal and interannual variability of summer bloom spatial extent. Such 
a wealth of observations from the MERIS historical data enabled the environmental factors, such as nutrient loading and meteorological conditions, to be examined for understanding the drivers of summer bloom variability. The results indicate that the surface layer eDIP loading available in February and March governed summer bloom abundance in all regions studied, while later spring $\mathrm{P}$, summer SST and PAR had relatively lower influence on the bloom abundance. The finding allows new insights into the development of early warning systems for summer phytoplankton blooms in the Baltic Sea.

Although MERIS data are no longer routinely acquired for global water monitoring, data continuity is now re-established through the newly launched Sentinel-3 OLCI. The transferability of the SPP algorithm to the improved spectral resolution of OLCI data supports better atmospheric correction schemes for both water constituent retrievals and phytoplankton phenology investigation over optically complex inland waters. This is of great importance to the development of consistent satellite-derived time series and to the validation of ecological models for the Baltic Sea. Also, the work supports the feasibility of applying similar approaches to investigate phytoplankton dynamics and their ecological responses to environmental perturbations over inland waters at regional and global scales.

\section{Acknowledgements}

The authors would like to express their sincere gratitude to Plymouth Marine Laboratory; Dr. Giorgio Dall'Olmo for his invaluable advice on this study and Steve Groom for his kind support. The authors would also like to thank ICES and HELCOM for providing the in situ datasets and ECMWF for supplying the ERA interim reanalysis data. The satellite imagery was provided by the European Space Agency. Financial support of this project is through Na- 
628 tional Key Research and Developmental Program of China (2017YFC0404705),

${ }_{629}$ National Natural Science Foundation of China $(51779157,51679153)$ and the ${ }_{630}$ UCL MAPS Dean's fund. 
Al-Naimi, N., Raitsos, D., Ben-Hamadou, R., \& Soliman, Y. (2017). Evaluation of Satellite Retrievals of Chlorophyll-a in the Arabian Gulf. Remote Sensing, 9,301 .

Alikas, K., \& Kratzer, S. (2017). Improved retrieval of Secchi depth for opticallycomplex waters using remote sensing data. Ecological Indicators, 77, 218-227.

Andersen, J. H., Axe, P., Backer, H., Carstensen, J., Claussen, U., FlemingLehtinen, V., Järvinen, M., Kaartokallio, H., Knuuttila, S., Korpinen, S., Kubiliute, A., Laamanen, M., Lysiak-Pastuszak, E., Martin, G., Murray, C., Møhlenberg, F., Nausch, G., Norkko, A., \& Villnäs, A. (2010). Getting the measure of eutrophication in the Baltic Sea: towards improved assessment principles and methods. Biogeochemistry, 106, 137-156.

ATBD (2011). Medium resolution imaging spectrometer (meris): Pixel classification algorithm theoretical basis document, .

Backer, H., Leppänen, J.-M., Brusendorff, A. C., Forsius, K., Stankiewicz, M., Mehtonen, J., Pyhälä, M., Laamanen, M., Paulomäki, H., Vlasov, N., \& Haaranen, T. (2010b). HELCOM Baltic Sea Action Plan - A regional programme of measures for the marine environment based on the Ecosystem Approach. Marine Pollution Bulletin, 60, 642-649.

Backer, L. C., McNeel, S. V., Barber, T., Kirkpatrick, B., Williams, C., Irvin, M., Zhou, Y., Johnson, T. B., Nierenberg, K., Aubel, M., LePrell, R., Chapman, A., Foss, A., Corum, S., Hill, V. R., Kieszak, S. M., \& Cheng, Y.-S. (2010a). Recreational exposure to microcystins during algal bloomsin two California lakes. Toxicon, 55, 909-921.

Behrenfeld, M. J. (2010). Abandoning sverdrup's critical depth hypothesis on phytoplankton blooms. Ecology, 91, 977-989. 
Brando, V. E., \& Dekker, A. G. (2003). Satellite hyperspectral remote sensing for estimating estuarine and coastal water quality. Geoscience and Remote Sensing, IEEE Transactions on, 41, 1378-1387. doi:10.1109/TGRS.2003. 812907.

Carstensen, J., \& Heiskanen, A.-S. (2007). Phytoplankton responses to nutrient status: application of a screening method to the northern baltic sea. Marine Ecology Progress Series, 336, 29-42.

Chen, Z., Hu, C., \& Muller-Karger, F. (2007a). Monitoring turbidity in Tampa Bay using MODIS/Aqua 250-m imagery. Remote Sensing of Environment, 109, 207-220.

Chen, Z., Muller-Karger, F. E., \& Hu, C. (2007b). Remote sensing of water clarity in Tampa Bay. Remote Sensing of Environment, 109, 249-259.

Chislock, M. F., Doster, E., Zitomer, R. A., \& Wilson, A. E. (2013). Eutrophication: Causes, Consequences, and Controls in Aquatic Ecosystems. Nature Education Knowledge, 4 .

Daewel, U., \& Schrum, C. (2013). Simulating long-term dynamics of the coupled North Sea and Baltic Sea ecosystem with ECOSMO II: Model description and validation. Journal Of Marine Systems, 119-120, 30-49. doi:10.1016/ j.jmarsys.2013.03.008.

Dall'Olmo, G., Brewin, R. J. W., Nencioli, F., Organelli, E., Lefering, I., Mckee, D., Röttgers, R., Mitchell, C., Boss, E., Bricaud, A., \& Tilstone, G. (2017). Determination of the absorption coefficient of chromophoric dissolved organic matter from underway spectrophotometry. Optics Express, 25, A1079.

Dee, D. P., Uppala, S. M., Simmons, A. J., Berrisford, P., Poli, P., Kobayashi, S., Andrae, U., Balmaseda, M. A., Balsamo, G., Bauer, P., Bechtold, P., Beljaars, 
A. C. M., van de Berg, L., Bidlot, J., Bormann, N., Delsol, C., Dragani, R., Fuentes, M., Geer, A. J., Haimberger, L., Healy, S. B., Hersbach, H., Hólm, E. V., Isaksen, L., Kållberg, P., Köhler, M., Matricardi, M., McNally, A. P., Monge-Sanz, B. M., Morcrette, J. J., Park, B. K., Peubey, C., de Rosnay, P., Tavolato, C., Thépaut, J. N., \& Vitart, F. (2011). The ERA-Interim reanalysis: configuration and performance of the data assimilation system. Quarterly Journal of the Royal Meteorological Society, 137, 553-597.

Elith, J., Leathwick, J. R., \& Hastie, T. (2008). A working guide to boosted regression trees. Journal of Animal Ecology, 77, 802-813.

Feng, L., Hu, C., Chen, X., Cai, X., Tian, L., \& Gan, W. (2012). Assessment of inundation changes of Poyang Lake using MODIS observations between 2000 and 2010. Remote Sensing of Environment, 121, 80-92.

Ferreira, J. G., Andersen, J. H., Borja, A., Bricker, S. B., Camp, J., Cardoso da Silva, M., Garcés, E., Heiskanen, A.-S., Humborg, C., \& Ignatiades, L. (2011). Overview of eutrophication indicators to assess environmental status within the European Marine Strategy Framework Directive. Estuarine Coastal And Shelf Science, 93, 117-131. doi:10.1016/j.ecss.2011.03.014.

Fleming-Lehtinen, V. (2007). HELCOM EUTRO: Development of tools for a thematic eutrophication assessment for two Baltic Sea sub-regions, the Gulf of Finland and the Bothnian Bay volume 13.

Fleming-Lehtinen, V., Andersen, J. H., Carstensen, J., ysiak Pastuszak, E., Murray, C., Pyhälä, M., \& Laamanen, M. (2015). Ecological Indicators. Ecological Indicators, 48, 380-388.

Friedman, J. H., \& Meulman, J. J. (2003). Multiple additive regression trees with application in epidemiology. Statistics in medicine, 22, 1365-1381. 
Gitelson, A. A., Gurlin, D., Moses, W. J., \& Barrow, T. (2009). A bio-optical algorithm for the remote estimation of the chlorophyll-a concentration in case 2 waters. Environmental Research Letters, 4, 045003.

Gower, J., Hu, C., Borstad, G., \& King, S. (2006). Ocean Color Satellites Show Extensive Lines of Floating Sargassum in the Gulf of Mexico. Geoscience and Remote Sensing, IEEE Transactions on, 44, 3619-3625.

Gower, J., King, S., Borstad, G., \& Brown, L. (2005). Detection of intense plankton blooms using the $709 \mathrm{~nm}$ band of the MERIS imaging spectrometer. International Journal Of Remote Sensing, 26, 2005-2012.

Grasshoff, K., Kremling, K., \& Ehrhardt, M. (2009). Methods of seawater analysis. John Wiley \& Sons.

HELCOM (2005). General guidelines on quality assurance for monitoring in the Baltic Sea. Manual for Marine Monitoring in the COMBINE Programme of HELCOM, (pp. 21-198).

HELCOM (2006). Development of tools for assessment of eutrophication in the Baltic Sea. Baltic Sea Environment Proceedings No. 104, (pp. 1-64).

HELCOM (2006). Eutrophication in the Baltic Sea. HELCOM Thematic Assessment Report, (pp. 1-34).

HELCOM (2007). HELCOM Baltic Sea Action Plan . Helsinki Commission for the Protection of the Baltic Marine Environment Helsinki, Finland, (pp. $1-101)$.

HELCOM (2009). Eutrophication in the Baltic Sea-An integrated thematic assessment of the effects of nutrient enrichment in the Baltic Sea region. Baltic Sea Environment Proceedings No. 115B, (pp. 1-152). 
Hu, C. (2009). A novel ocean color index to detect floating algae in the global oceans. Remote Sensing of Environment, 113, 2118-2129.

Hu, C., \& Feng, L. (2017). Modified MODIS fluorescence line height data product to improve image interpretation for red tide monitoring in the eastern Gulf of Mexico. Journal of Applied Remote Sensing, 11, 012003.

Hu, C., Lee, Z., Ma, R., Yu, K., Li, D., \& Shang, S. (2010). Moderate Resolution Imaging Spectroradiometer (MODIS) observations of cyanobacteria blooms in Taihu Lake, China. Journal Of Geophysical Research-Oceans, 115, C04002.

Hu, C. M., Chen, Z. Q., Clayton, T. D., Swarzenski, P., Brock, J. C., \& MullerKarger, F. E. (2004). Assessment of estuarine water-quality indicators using MODIS medium-resolution bands: Initial results from Tampa Bay, FL. Remote Sensing of Environment, 93, 423-441.

Hunter, P. R. (1998). Cyanobacterial toxins and human health. Journal of Applied Microbiology, 84, 35-40.

Janssen, F., Neumann, T., \& Schmidt, M. (2004). Inter-annual variability in cyanobacteria blooms in the Baltic Sea controlled by wintertime hydrographic conditions. Marine ecology progress series. Oldendorf, 275, 59-68.

Kahru, M., \& Elmgren, R. (2014). Multidecadal time series of satellite-detected accumulations of cyanobacteria in the Baltic Sea. Biogeosciences, 11, 36193633.

Kahru, M., Savchuk, O. P., \& Elmgren, R. (2007). Satellite measurements of cyanobacterial bloom frequency in the Baltic Sea: interannual and spatial variability. Marine Ecology Progress Series, 343, 15-23.

Kiirikki, M., Inkala, A., Kuosa, H., Pitkänen, H., Kuusisto, M., Sarkkula, J. et al. (2001). Evaluating the effects of nutrient load reductions on the biomass 
of toxic nitrogen-fixing cyanobacteria in the gulf of finland, baltic sea. Boreal Environment Research, 6, 131-146.

Kononen, K. (1992). Dynamics of the toxic cyanobacterial blooms in the Baltic Sea volume 216 .

Kutser, T. (2004). Quantitative detection of chlorophyll in cyanobacterial blooms by satellite remote sensing. Limnology And Oceanography, 49, 21792189.

Kutser, T., Metsamaa, L., Strombeck, N., \& Vahtmae, E. (2006). Monitoring cyanobacterial blooms by satellite remote sensing. Estuarine Coastal And Shelf Science, 67, 303-312.

Lilover, M. J., \& Stips, A. (2008). The variability of parameters controlling the cyanobacteria bloom biomass in the Baltic Sea. Journal Of Marine Systems, 74, S108-S115.

Lotze, H. K., Lenihan, H. S., Bourque, B. J., Bradbury, R. H., Cooke, R. G., Kay, M. C., Kidwell, S. M., Kirby, M. X., Peterson, C. H., \& Jackson, J. B. (2006). Depletion, degradation, and recovery potential of estuaries and coastal seas. Science, 312, 1806-1809.

Lundberg, C., Lönnroth, M., von Numers, M., \& Bonsdorff, E. (2005). A multivariate assessment of coastal eutrophication. Examples from the Gulf of Finland, northern Baltic Sea. Marine Pollution Bulletin, 50, 1185-1196. doi:10.1016/j.marpolbul.2005.04.029.

Matthews, M. W. (2014). Eutrophication and cyanobacterial blooms in South African inland waters: 10years of MERIS observations. Remote Sensing of Environment, 155, 161-177. 
Matthews, M. W., Bernard, S., \& Robertson, L. (2012). An algorithm for detecting trophic status (chlorophyll-a), cyanobacterial-dominance, surface scums and floating vegetation in inland and coastal waters. Remote Sensing of Environment, 124, 637-652.

Matthews, M. W., Bernard, S., \& Winter, K. (2010). Remote sensing of cyanobacteria-dominant algal blooms and water quality parameters in Zeekoevlei, a small hypertrophic lake, using MERIS. Remote Sensing of Environment, 114, 2070-2087.

Moses, W. J., Gitelson, A. A., Berdnikov, S., \& Povazhnyy, V. (2009). Estimation of chlorophyll- aconcentration in case II waters using MODIS and MERIS data - successes and challenges. Environmental Research Letters, 4, 045005 .

Niemi, A. (1979). Blue-green algal blooms and n: $\mathrm{P}$ ratio in the baltic sea. Acta Botanica Fennica, 110, 57-61.

OSPAR (2005). Common Procedure for the Identification of the Eutrophication Status of the OSPAR Maritime Area. Technical Report.

OSPAR (2008). Eutrophication Status of the OSPAR Maritime Area, Second OSPAR Integrated Report. OSPAR publication, 372, 1-108.

Österblom, H., Hansson, S., Larsson, U., Hjerne, O., Wulff, F., Elmgren, R., \& Folke, C. (2007). Human-induced Trophic Cascades and Ecological Regime Shifts in the Baltic Sea. Ecosystems, 10, 877-889. doi:10.1007/ s10021-007-9069-0.

Paerl, H. W. (1997). Coastal eutrophication and harmful algal blooms: Importance of atmospheric deposition and groundwater as "new" nitrogen and other nutrient sources. Limnology And Oceanography, 42, 1154-1165. 
Painting, S. J., Devlin, M. J., Rogers, S. I., Mills, D. K., Parker, E. R., \& Rees, H. L. (2005). Assessing the suitability of OSPAR EcoQOs for eutrophication vs ICES criteria for England and Wales. Marine Pollution Bulletin, 50, 1569-1584. doi:10.1016/j.marpolbul.2005.06.042.

Palmer, S. C. J., Odermatt, D., Hunter, P. D., Brockmann, C., Présing, M., Balzter, H., \& Tóth, V. R. (2015). Satellite remote sensing of phytoplankton phenology in Lake Balaton using 10years of MERIS observations. Remote Sensing of Environment, 158, 441-452.

Platt, T., White, G. N., III, Zhai, L., Sathyendranath, S., \& Roy, S. (2009). The phenology of phytoplankton blooms: Ecosystem indicators from remote sensing. Ecological Modelling, 220, 3057-3069.

Pond, S., \& Pickard, G. L. (1983). Introductory dynamical oceanography. Gulf Professional Publishing.

Pyhälä, M., Fleming-Lehtinen, V., Lysiak-Pastuszak, E., Carstens, M., Leppänen, J.-M., Murray, C., \& Andersen, J. (2013). Eutrophication status of the Baltic Sea 2007-2011 A concise thematic assessment, . (pp. 1-25).

Raitsos, D. E., Lavender, S. J., Pradhan, Y., Tyrrell, T., Reid, P. C., \& Edwards, M. (2006). Coccolithophore bloom size variation in response to the regional environment of the subarctic north atlantic. Limnology and oceanography, $51,2122-2130$.

Sellner, K. G. (1997). Physiology, ecology, and toxic properties of marine cyanobacteria blooms. Limnology And Oceanography, 42, 1089-1104.

Simis, S., Peters, S., \& Gons, H. J. (2005). Remote sensing of the cyanobacterial pigment phycocyanin in turbid inland water. Limnology And Oceanography, $50,237-245$. 
Smayda, T., \& Trainer, V. (2010). Dinoflagellate blooms in upwelling systems: Seeding, variability, and contrasts with diatom bloom behaviour. Progress in Oceanography, 85, 92-107.

Smith, V. H. (2003). Eutrophication of freshwater and coastal marine ecosystems a global problem. Environmental Science and Pollution Research, 10, 126-139. doi:10.1065/esor2002.12.142.

Swedish EPA (2008). The Economic Value of Ecosystem Services Provided by the Baltic Sea and Skagerrak-Existing Information and Gaps of Knowledge. Swedish EPA Report, 5874.

UNESCO (1981). International oceanographic tables,vol. 3, . 39.

Vermote, E. F., Tanré, D., Deuze, J. L., Herman, M., \& Morcette, J.-J. (1997). Second simulation of the satellite signal in the solar spectrum, 6S: An overview. IEEE Transactions on Geoscience and Remote Sensing, 35, $675-686$.

Wasmund, N. (1997). Occurrence of cyanobacterial blooms in the Baltic Sea in relation to environmental conditions. Internationale Revue der gesamten Hydrobiologie und Hydrographie, 82, 169-184.

Wasmund, N., Göbel, J., \& Bodungen, B. v. (2008). 100-years-changes in the phytoplankton community of kiel bight (baltic sea). Journal of Marine Systems, 73, 300-322.

Wasmund, N., Nausch, G., \& Matthäus, W. (1998). Phytoplankton spring blooms in the southern Baltic Sea-spatio-temporal development and longterm trends. Journal Of Plankton Research, 20, 1099-1117.

Wasmund, N., \& Uhlig, S. (2003). Phytoplankton trends in the baltic sea. ICES Journal of Marine Science: Journal du Conseil, 60, 177-186. 
${ }_{854} \mathrm{Wu}$, J. (1982). Wind-stress coefficients over sea surface from breeze to hurricane. Journal of Geophysical Research: Oceans (1978-2012), 87, 9704-9706.

Yelland, M., \& Taylor, P. K. (1996). Wind stress measurements from the open ocean. Journal of Physical Oceanography, 26, 541-558.

Yurkovskis, A., Kostrichkina, E., \& Ikauniece, A. (1999). Seasonal succession and growth in the plankton communities of the gulf of riga in relation to long-term nutrient dynamics. Hydrobiologia, 393, 83-94.

Zhang, D., Lavender, S., Muller, J.-P., Walton, D., Karlson, B., \& Kronsell, J. (2017). Determination of phytoplankton abundances (Chlorophyll- a ) in the optically complex inland water - The Baltic Sea. Science of the Total Environment, 601-602, 1060-1074.

Zhang, Y., Ma, R., Zhang, M., Duan, H., Loiselle, S., \& Xu, J. (2015). FourteenYear Record (2000-2013) of the Spatial and Temporal Dynamics of Floating Algae Blooms in Lake Chaohu, Observed from Time Series of MODIS Images. Remote Sensing, 7, 10523-10542. 